\title{
A CLINICAL STUDY OF SIDDHA HERBAL PREPARATION - M V KASHAYAM FOR THE TREATMENT, CONTROL, AND MANAGEMENT OF COVID-19
}

\begin{abstract}
MALARKANNAN SP ${ }^{1}$, DHARUMARAJAN P ${ }^{2}$, HARIYOHESH MK ${ }^{3}$
${ }^{1}$ Department of Rural Development Science, Arul Anandar College, Madurai, Tamil Nadu, India. ${ }^{2}$ Department of Indian Medicine and Homeopathy, Government Hospital, Virudhunagar, Tamil Nadu, India. ${ }^{3}$ Medical School Foundation, BS MD Scholar, Daevo Medical School Foundation Inc, Medical School Dr, Poblacion district, Davo City, 8000 Davo del Sur, Philippines. Email: drspmalarkannan@gmail.com
\end{abstract}

Received: 23 March 2021, Revised and Accepted: 29 April 2021

ABSTRACT

Objective: At present, the pandemic COVID-19 by novel coronavirus causing severe mortality and losses to the human and no specific medicine to cure. Siddha is an ancient system of medicine used in using a variety of medicinal herbs to cure diseases of viral and unknown origin.

Method: The herbal medicine M V Kashayam prepared as per Siddha formula administered at the dose rate of $150 \mathrm{ml}$ for every 6-h interval for Reverse Transcription-Polymerase Chain Reaction (RT - PCR) positive patients

Results: The prepared MV Kashayam can able to provide RT-PCR negative in $87.5 \%$ of cases within $4-6$ days and $97.5 \%$ negatives in 12 days. The body temperature, Oxygen saturation level (SPO2), and respiration level become normal within 3 days.

Conclusion: The Siddha medicine, MV kashayam may be used as herbal medicine to treat the COVID-19 patients for earlier recovery and as a preventive measure to enhance immunity.

Keywords: COVID, Siddha preparation, MV kashayam, Treatment.

(C) 2021 The Authors. Published by Innovare Academic Sciences Pvt Ltd. This is an open access article under the CC BY license (http://creativecommons.org/ licenses/by/4.0/) DOI: http://dx.doi.org/10.22159/ajpcr.2021v14i6.41582. Journal homepage: https://innovareacademics.in/journals/index.php/ajpcr

\section{INTRODUCTION}

India has rich indigenous herbal resources, about 20,000 plant species, of which about 2500 are of medicinal value [1] and medicinal plants are generally known as "Chemical Goldmines." The Indian subcontinent recognized as a herbal hub and herbal formulations have been used for several years. Many primary and secondary metabolites of the herbs are important in many pharmaceutical preparations. Of the 250,000 higher plant species on earth, more than 80,000 are medicinal in nature [2]. Increasing population size, drug insufficiency, higher cost, adverse effects, and ineffectiveness of many allopathic drugs escort to the significance of herbal medicines to combat many diseases [3]. According to the WHO, COVID-19 is an infectious pandemic disease caused by a newer type of coronavirus, is a subfamily Coronavirinae in the family Coronaviridae. Seven types of coronaviruses, namely, 229E, NL63, OC43, HKU1, MERS-CoV, SARS-CoV, and SARS-CoV-2 are mainly affecting human being.

The SARS-CoV-2 virus is spherical and has spike-like proteins protruding from their surfaces [4] which attach to the human cells and spread through the nasal discharge or droplets of sneezing and saliva of the infected person. Interpersonal distance, face mask, washing hand sanitizers, hand washes, etc., are followed to control the spread of the virus. Further, the public is advised to boost immunity by consuming nutritious and balanced food. The affected people may exhibit the symptoms in 2-14 days. The prominent symptoms are dry cough, sore throat, loss of taste and smell, fever, muscle pain, respiratory distress, etc. [5]. Infection is severe in old people with chronic illness, namely, diabetes, cardiovascular disease, and chronic respiratory problems.

To improve the immunity level, health officials recommend herbal drink based on Siddha formulation [6]. At present, there is no specific medicine to treat the COVID-19 and hence this study aimed to analyze the antiviral activity of Herbal preparation M V Kashayam (MV kashayam) in the management, treatment, and control of the COVID-19 patients.

\section{METHODS}

In this clinical trial, a total of 40 COVID-19 patients of both sexes within the age group of 15-60 years admitted to the government hospital, Aruppukottai, Virudhunagar, Tamil Nadu, India, were investigated during the period of 25 November 2020-21 January 2021 with the report of RT-PCR positive patients after informing the consent form details. The study was carried out as per order No. 407/A3/2019, Director of Indian Medicine, Chennai, dated 29 September 2020 and as per registration No.REF/2020/11/038104 in the clinical trial regularity authority of India and IEC approval of VNGRSLD20190001803 dated 06 September 2020. The required herbals were collected from the Western Ghats and herbal market for the preparation of "M V kashayam" as per the traditional Siddha formula [6]. The temperature of the patients was measured with non-contact infrared CP-MED thermometer model No GP 200, China, $\mathrm{SPO}_{2}$ level with fingertip Pulse Oximeter model No Q3, China. The SARS-COV-2 Test kid (real-time PCR) collected from Xiamen Zeesan Biotech Co. Ltd., China.

\section{Preparation of kashayam}

Boiling the drug in water for a definite period and reducing it to a specific quantity is called Kashayam. In this preparation, herbs of matured plants and their roots were collected with caution. They were cleaned with potable water to remove the soil and extraneous matter presented over them. The excess water presented over them was whipped off with a clean cotton cloth. After ensuring the cleanliness of the ingredients, they were cut into small pieces and dried under the shadow. After drying to a sufficient level, the herbs of equal quantity were taken as per the traditional Siddha formula. The herbs were pounded into the form of coarse powder. Add $650 \mathrm{ml}$ of water and allow the herbs to completely soak in water for 2-3 h. Start boiling the content in a wide mouth pot under a mild flame without the lid helps to evaporate the water. Stir the contents with a ladle continuously. Boil the content until it reduces its volume to $150 \mathrm{ml}$ of its initial quantity. Filter the supernatant with a clean cloth immediately. The prepared MV kashayam can be used within $3 \mathrm{~h}$ as per recommended dose. The filtrate contains most of the active 
principles of the herb in water-soluble nature and these forms were readily absorbed from the intestine results in faster action. Immediate consumption is one of the best methods to get the maximum benefits of these herbs. The combination of herbs for this kashayam preparation was selected based on mutual compatibility and collective effectiveness to get maximum effect against a particular type of disease and similarly, one herb will mask the side effect of the other herb to eradicate the unwanted effects.

\section{Data analysis}

For the RT-PCR positive patients, after carefully understand the consent form details and sign in it, the patients were enrolled in the study, a separate file for each patient will be maintained, and all forms will be kept in the file. The study number and patient's number will be entered on the top of the file for easy identification. Whenever the patients visit OPD during the study period, necessary entries will be made in the assessment forms. The data were analyzed as per the descriptive type of statistical method [7]. The clinical trial study was carried out with a descriptive study design model.

\section{RESULTS}

COVID-19 is a pandemic disease for which no pool-proof medicines are available as a treatment. This study is aimed to develop a herbal medicine to treat, control and management of this disease. The study was carried out in patients within the age group of 15 to 60 years. This study has a minimum age group of patient been 17 years and a maximum of 60 years with a mean value of 38.4 \pm 12.7 . Among the patients 5 percent were less than the age group of 20 years, 50 percent were within the age group of 20 to 40 years, and 45 percent were within the age group of 41 to 60 years. The clinical trial was carried out in both the sex of the patients to avoid gender error and 72.5 percent were male and 27.5 percent were female patients (Table 1).

The table shows that out of 40 respondents, 11(27.5\%) are female, 29 $(72.5 \%)$ are male.

The table shows that out of 40 respondents $2(5.0 \%)$ are below 20 yrs, $20(50 \%)$ are $20-40$ yrs, $18(45 \%)$ are $41-60$ yrs.

Among the selected patients some of them have history of Co-morbidity conditions along with the normal clinical symptoms like Anaemia Widal +ve menorrhagia, chronicpulmonary obstructive pulmonary disease, hypertension with chronic renalfailure, Fatty Lever + Cholelithiasis andepilepsy around 2.5 percent, diabetes mellitus 12.5 percent, diabetes mellitus with hypertension 10 percent and patients with hypertension alone 5 percent (Table 2).

The normal temperature of humans is 97-98.60F. While on the first day of admission all the patients have a temperature above the normal valve. On the second day, only one patient is having a temperature level of $1000 \mathrm{~F}$ and the remaining patients had normal temperature, on the third day itself irrespective of their temperature level all the patients returned to their normal temperature (Table 3).

The analysis of SPO2 level in COVID 19 patients treated with MV kashayam showed complete recovery in seven days of treatment. The normal value for SPO2 is $98-100$ percent as per the pamphlet of the Tamilnadu government. It is clear from the table that at the time of admission all the patients have SPO2 level less than the normal level but from the second day onwards there is a gradual recovery in the condition of 17 patients by way of an increase in the SPO2 level, on the third day it is has raised to 18 , on the fourth day it is 21 patients, the fifth day it is 28 patients, the sixth day it is 29 patients and on the seventh day, all the 40 patients have the normal temperature value of 98.0 to 100 percent of SPO2 level (Table 4).

In the present study, the patients regained their respiration rate from the second day onwards, a gradual increase in the respiratory rate reported in 11 persons, on the third day and it is raised to 29 , on the fourth day it is 38 and from fifth day onwards all the patients are within the normal level of respiration rate of 14-16 per minute and the result is explained in the bar diagram (Table 5). The result showed that out of 100 percent, 97.5 percent of patients recovered after administration MV kashayam.

Out of 40 respondents, 19 respondents (47.5\%) are cured and got negative results on the fourth day, 5 respondents $(12.5 \%)$ are cured and got negative results on the fifth day, 11 respondents $(27.5 \%)$ are cured on the sixth day, 01 respondents $(2.5 \%)$ is cured on the ninth and twelfth day, 02 respondents $(5 \%)$ are cured on the eleventh day and one respondent $(2.5 \%)$ is cured on twelfth day with RT- PCR negative (Table 6). The remaining only one respondent is not cured up to the sixth day and the patient left the treatment due to personnel reasons. The result indicated that the Siddha herbal medicine MV kashayam has effective against corona virus in patients with various levels of infection [12] reported that the combination of Siddha drugs has effective against deadly viruses.

The value of the RdRp gene of COVID positive patients was varied from 12.62 to 34.3 and for the N genes, the values ranged from 11.28 to 32.26. Based on that finding (Wisconsin Veterinary Diagnostic Laboratory, 2018) it was concluded that among the 40 patients 38 patients have come under the strong positive cases category and two of them in moderate condition and none of them in mild or week positive condition. In all the recovered patients the results were above 40 .

Table 1: Age and sex details of treated patients

\begin{tabular}{llllll}
\hline Age(in years) & $\begin{array}{l}\text { Age group } \\
\text { (in years) }\end{array}$ & $\mathbf{n}(\%)$ & Gender & $\mathbf{n}(\%)$ \\
\hline $\begin{array}{l}\text { Total } \\
\text { patients }\end{array}$ & 40 & $<20$ & $2(5.0)$ & Male & $29(72.5)$ \\
$\quad$ Minimum & 17 & $20-40$ & $20(50.0)$ & Female & $11(27.5)$ \\
Maximum & 60 & $41-60$ & $18(45.0)$ & Total & $40(100.0)$ \\
Mean $\pm S D$ & $38.4 \pm 12.7$ & Total & 40 & & \\
& & & $(100.0)$ & & \\
\hline
\end{tabular}

Table 2: History of co-morbidity condition

\begin{tabular}{ll}
\hline History of co-morbidity condition & $\mathbf{n}(\%)$ \\
\hline Anemia Widal +ve menorrhagia & $1(2.5)$ \\
COPD* & $1(2.5)$ \\
DM$^{*}$ & $5(12.5)$ \\
DM +HT* & $4(10)$ \\
HT* & $2(5)$ \\
HT+ CRF* & $1(2.5)$ \\
Epilepsy & $1(2.5)$ \\
Fatty Lever +Cholelithiasis & $1(2.5)$ \\
Total & 16 \\
\hline
\end{tabular}

*COPD: Chronic obstructive pulmonary disease, *HT: Hypertension,

*DM: Diabetes mellitus, ${ }^{*}$ CRF: Chronic renal failure

Table 3: Symptoms of temperature and days in recovery after administration of MV Kashayam (7 days results)

\begin{tabular}{|c|c|c|c|c|c|c|c|c|}
\hline \multirow{2}{*}{$\begin{array}{l}\text { Number of } \\
\text { days }\end{array}$} & \multicolumn{7}{|c|}{ Temperature $\left({ }^{\circ} \mathrm{F}\right)$ ËšC } & \multirow[t]{2}{*}{ Total } \\
\hline & 98.0 & 98.2 & 98.4 & 98.6 & 99.0 & 100.0 & 102.0 & \\
\hline I Day & 1 & 0 & 7 & 27 & 3 & 1 & 1 & 40 \\
\hline II Day & 1 & 0 & 14 & 24 & 0 & 1 & 0 & 40 \\
\hline III Day & 1 & 1 & 15 & 23 & 0 & 0 & 0 & 40 \\
\hline IV Day & 2 & 1 & 12 & 25 & 0 & 0 & 0 & 40 \\
\hline V Day & 0 & 3 & 13 & 24 & 0 & 0 & 0 & 40 \\
\hline VI Day & 0 & 0 & 13 & 27 & 0 & 0 & 0 & 40 \\
\hline VII Day & 0 & 2 & 10 & 28 & 0 & 0 & 0 & 40 \\
\hline
\end{tabular}


Table 4: Recovery status of patients with spo2 level after administration of MV Kashayam

\begin{tabular}{|c|c|c|c|c|c|c|c|c|c|c|c|c|c|}
\hline \multirow[t]{2}{*}{ No of Days } & \multicolumn{13}{|c|}{$\mathrm{SPO}_{2} \%$} \\
\hline & $85 \%$ & $88 \%$ & $90 \%$ & $92 \%$ & $93 \%$ & $94 \%$ & $95 \%$ & $96 \%$ & $97 \%$ & $98 \%$ & $99 \%$ & $100 \%$ & Total \\
\hline Day I & 1 & 1 & 2 & 5 & 3 & 9 & 8 & 5 & 6 & 0 & 0 & 0 & 40 \\
\hline Day III & 0 & 0 & 0 & 0 & 1 & 0 & 1 & 3 & 9 & 18 & 8 & 0 & 40 \\
\hline Day IV & 0 & 0 & 0 & 0 & 0 & 0 & 2 & 3 & 8 & 21 & 5 & 1 & 40 \\
\hline Day V & 0 & 0 & 0 & 0 & 0 & 0 & 0 & 0 & 0 & 30 & 10 & 0 & 40 \\
\hline Day VI & 0 & 0 & 0 & 0 & 0 & 0 & 0 & 0 & 0 & 31 & 9 & 0 & 40 \\
\hline Day VII & 0 & 0 & 0 & 0 & 0 & 0 & 0 & 0 & 0 & 29 & 11 & 0 & 40 \\
\hline
\end{tabular}

Regarding the RdRp Gene value, the minimum is zero and the maximum is 34.30. The mean value of the RdRp Gene value is 18.49 and the standard deviation is 6.27 . The p-value for the RdRp gene is 0.515 and itis more than 0.05 (5\% level of significance) and showed a null hypothesis. The $\mathrm{p}$-value of the $\mathrm{N}$ gene is 0.088 and it is morethan 0.05 ( $5 \%$ level of significance), exhibited a null hypothesis.

\section{DISCUSSION}

Among the patients which 72.5 percent were male and 27.5 percent were female patients during the study period reported with positive RT- PCR test, it may be due to free movement and exposure of male population than that of female population may be the reason for the higher number of male patients than that of female patients. The result was following [8] reported that the prevalence of COVID-19 was higher in males $(\mathrm{N}=102)$ compared with females $(\mathrm{n}=87)$, and the proportion of male cases in the critical severe cases were significantly higher may be due to greater exposure of male patients than that of female patients. Similarly, the incidence of COVID 19 is increased as age advances.

Amongthe selected patients some of them have Co-morbidity conditions along withthe normal history of clinical symptoms like Anaemia Widal +ve menorrhagia, chronicpulmonary obstructive pulmonary disease, hypertension with chronic renal failure, Fatty Lever + Cholelithiasis and epilepsy around 2.5 percent, diabetes mellitus 12.5 percent, diabetes mellitus with hypertension 10 percent and patients with hypertension alone 5 percent.Hypertension, diabetes and coronary heart disease were themost common co-morbidities in COVID 19 affected patients [8].

The normal temperature of humans is 97-98.60F. While on the first day of admission all the patients have a temperature above the normal valve. After administration of the drug on the first day of treatment out of 40 patients thirty-eight of the patients, the temperature was within the normal range of $990 \mathrm{~F}$, only two of them having a temperature of $100 \mathrm{OF}$ and $1020 \mathrm{~F}$ respectively. On the second day, only one patient is having a temperature level of $100 \mathrm{0F}$ and the remaining patients had a normal temperature, on the third day itself irrespective of their temperature level all the patients recoverd to their normal temperature. The MV Kashayam has efficiently controlled the temperature in corona virusinfected patients. The bar diagram also shows the visualization level of the temperature of patients.

Viral infection of the respiratory system typically provokes inflammation and stimulation of sensory receptors, inducing transmission of afferent impulses to the respiratory centres [9]. If the virus involves the alveoli, it may produce hypoxemia [10]. At present, respiratory and ventilator support are standard treatments for respiratory conditions associated with COVID-19. Unfortunately, despite such treatments of COVID-19 patients with respiratory conditions, a high mortality rate is still being observed [11]. The analysis of SPO2 level in COVID 19 patients treated with MV kashayam showed complete recovery in seven days of treatment. The normal value for SPO2 is 98-100 percent as per the pamphlet of the Tamilnadu government. It is evident from the table, at the time of admission all the patients have SPO2 level less than the normal level but from the
Table 5: Recovery rate of respiration in COVID patients after administration of MV kashayam

\begin{tabular}{llllllll}
\hline \multirow{2}{*}{ No of days of treatment } & \multicolumn{9}{c}{ Respiratory rate (per minutes) } & \multirow{2}{*}{ Total } \\
\cline { 2 - 7 } & $\mathbf{1 4}$ & $\mathbf{1 5}$ & $\mathbf{1 6}$ & $\mathbf{1 8}$ & $\mathbf{2 0}$ & $\mathbf{2 2}$ & \\
\hline I Day & 0 & 0 & 0 & 11 & 17 & 12 & 40 \\
II Day & 1 & 0 & 10 & 18 & 11 & 0 & 40 \\
III Day & 1 & 1 & 27 & 11 & 0 & 0 & 40 \\
IV Day & 11 & 4 & 23 & 2 & 0 & 0 & 40 \\
V Day & 7 & 5 & 28 & 0 & 0 & 0 & 40 \\
VI Day & 7 & 7 & 26 & 0 & 0 & 0 & 40 \\
VII Day & 5 & 0 & 35 & 0 & 0 & 0 & 40 \\
\hline
\end{tabular}

second day onwards a gradual recovery noticed in 17 patients with an increase in the SPO2 level, on third day it raised to 18, on fourth day it is 21 patients, the fifth day it is 28 patients, the sixth day it is 29 patients and on the seventh day, all the 40 patients have the normal temperature value of 98.0 to 100 percent of SPO2 level. It gives a clear indication that the saturation level of oxygen in the blood is increased to a normal level within the seven days after using MV Kashayam irrespective of the stage of infection.

The pathology in COVID-19 patients is very unlike other viral cases of pneumonia and reported that the currently employed therapies are highly ineffective and also hypothesized that a series of alternative treatment strategies for treating respiratory conditions will significantly improve tissue oxygenation among COVID-19 patients [11]. In the current study, the rate of recovery of respiration in COVID patients has tremendously increased after taking MV Kashayam. The normal value for respiratory rate in the human being is $14-16$ per minute as per the pamphlet of the Tamilnadu government. It is clear from the table that at the time of admission all the patients have a respiratory rate below (dyspnea) the normal level. The patients get recovery in their respiration rate from the second day onwards, a gradual increase in the respiratory rate reported in 11 persons, on the third day and it is raised to 29 , on the fourth day it is 38 and from fifth day onwards all the patients are within the normal level of respiration rate of 14 16 per minute. It can be understandable that the level of respiratory rate is normal within the fifth day after consuming MV kashayam.

The above table explains that the number of days that coronavirus affected patients with RT- PCR positive cases has been curedwith RTPCR negative result after treatment with the Siddha drug MV Kashayam. The result shows that out of 100 percent 97.5 percent of patients cured using MV kashayam.

Out of 40 patients, $19(47.5 \%)$ are cured and got negative results on the fourth day, $5(12.5 \%)$ are cured and got negative results on the fifth day, $11(27.5 \%)$ are cured on the sixth day, $01(2.5 \%)$ has been cured on the nine and twelfth day, $02(5 \%)$ are cured on the eleventh day and one $(2.5 \%)$ cured on twelfth day by way of RT- PCR negative. The remaining only one patient is not cured up to the sixth day and the patient left the treatment due to personnel reasons.The result proved that the Siddha herbal medicine has effective against corona virus in patients with wide intensity level of infection [12] reported the combination of Siddha drug has effective against the deadly viruses. 
Table 6: Recovery status of COVID patients with RT-PCR negative after treatment with MV kashayam

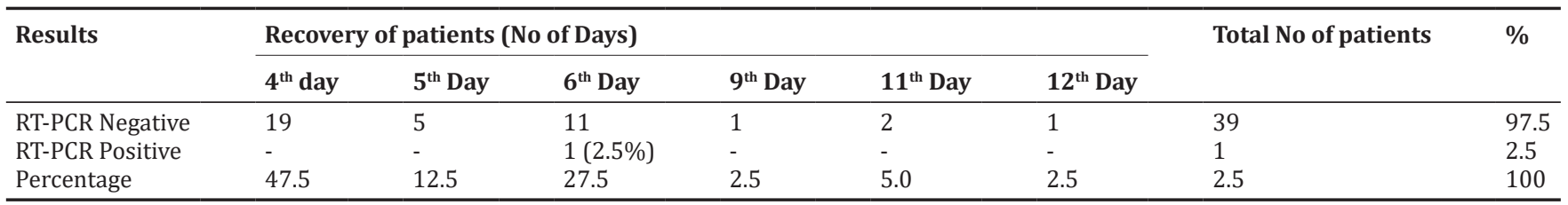

In a RT-PCR assay, a positive reaction is detected by the accumulation of a fluorescent signal Ct (cycle threshold) and its level can be calculated by the number of cycles required for the fluorescent signal to cross the threshold. Ct values are inversely proportional to the amount of target COVID nucleic acid in the sample. WVDL (Wisconsin Veterinary Diagnostic Laboratory, 2018) real-time assays undergo 40 cycles of amplification. They reported thatCts $<=29$ are strong positive reactions indicative of abundant target COVID nucleic acid in the sample. Cts of 30-37 is positive reactions indicative of a moderate level of target COVID nucleic acid in the sample. Cts of 38-40 is weak reactions indicative of minimal amounts of targeting COVID nucleic acid which could represent an infection state or environmental contamination. The value of the RdRp gene of COVID positive patients wasvaried from 12.62 to 34.3 and for the $\mathrm{N}$ genes, values ranged from 11.28 to 32.26 . Based on that finding it was concluded that among the 40 patients 38 patients have come under the strong positive cases category and two of them in moderate condition and none of them in mild or week positive condition. In all the recovered patients the results were above 40 .

The mean value of the RdRp Gene value is18.49 and the standard deviation is 6.27. The p-value for the RdRp gene is 0.515 and itis more than $5 \%$ level of significance and concluded that between gender and the RdRpgene value of coronavirus affected persons had no significant difference. Interpretation can be made that, the corona virus disease infect all peoples irrespective of gender.

\section{CONCLUSION}

The investigators acknowledge the Government of Tamil Nadu for permitting to carry out the study in the reputed government hospitals. Based on the clinical findings, it is concluded that the developed MV Kashayam has proved to control and cure the COVID-19 patients of both sexes, any age group, any level of severity of the infection, and also patients with co-morbidity condition within the period of 4-6 days with $87.5 \%$ RT-PCR negative without any supplements and side effects and it proved by clinical findings. Similarly, this drug is effective at any stage of severity in the clinical condition of the patients from strongly positive to mild positive condition. Hence, it is recommended that the MV Kashayam is a valuable trustworthy Siddha drug to prevent, manage, and treat COVID-19 patients.

\section{DECLARATIONS}

\section{Approvals}

The clinical trial was conducted with due approval from the Director of Indian Medicine, Chennai, as per order No. 407/A3/2019, dated $29 / 09 / 2020$ and registration in the clinical trial regularity authority of India as per No.REF/2020/11/038104 and IEC approval of VNGRSLD20190001803 dated 06/09/2020.

\section{Consent}

The written consent was obtained from the patients for conducting of clinical trial with the developed Siddha medicine, M V Kashayam.

\section{ACKNOWLEDGMENT}

The investigators' thanks to the Health Secretary, Director of Indian Medicine and Homeopathy, Government of Tamil Nadu, Director General of CCRS, Government of India for giving necessary permission and support to carry out the research work in a reputed institution.

\section{AUTHORS' CONTRIBUTIONS}

The authors jointly formulated a new herbal drug combination based on the Siddha system of medicine (Indian system of medicine) and developed a Kashayam. Preparation of kashayam, literature review, data analysis, and drafting and finalizing of the manuscript to be published was done by Dr. Malarkannan SP and supervision of the clinical trial, collection of consent forms, and data collections done by Dr. Dharumarajan P and Hariyohesh MK.

\section{CONFLICTS OF INTEREST}

The authors have no conflicts of interest.

\section{AUTHORS' FINDING}

The authors conducted a clinical trial with the developed $\mathrm{M} \mathrm{V}$ Kashayam of herbal drug combination on COVID-19 positive patients with due permission from competent authorities and concluded that the developed MV Kashayam with herbal combination may have concrete results to practice for management, prevention, and treatment of COVID-19 patients.

\section{Funding agency}

There are no funding sources.

\section{REFERENCES}

1. Kartikeyan J, Rekha V,Giftson RV. Characterization of bioactive compounds in Costus speciosus (Koen.) by reverse-phase HPLC. Int J Pharm Sci Res 2012;3:1461-5.

2. Thomas J. Medicinal and Aromatic Plant Research in India. In: Training Course on Industrial Exploitation of Indigenous Medicinal and Aromatic Plants. Beijing, China: UNDP, Proceeding; 1997. p. 17-27.

3. Panda D, Kumar DS, Kumar DG. Phytochemical examination and antimicrobial activity of various solvent extracts and the selected isolated compounds from roots of Tragia involucrata Linn. Int J Pharm Sci Drug Res 2012;4:44-8.

4. Li F. Structure, function, and evolution of coronavirus spike proteins. Annu Rev Virol 2016;3:237-61.

5. Yousef A, Sepandi M, Taghdir M, Hosamirudsari H. Determine the most common clinical symptoms in COVID-19 patients: A systematic review and meta-analysis. J Prev Med Hyg 2020;61:E304-12.

6. Malarkannan SP, Dharumaraj P. Anti-inflammatory activity of siddha preparation modivaer kashayam as a proposed remedy for management and treatment of Covid 19. Int J Res Anal Rev 2020;7:756-9.

7. Gupta SP. Statistical Methods. New Delhi: Sulthan Chand and Sons; 1997.

8. Jun Mi, Zhong W, Huang C, Zhang W, Tan L, Ding L. Gender, age and comorbidities as the main prognostic factors in patients with COVID-19 pneumonia. Am J Transl Res 2020;12:6537-48.

9. Preas HL, Jubran A, Vandivier RW, Reda D, Godin PJ, Banks SM, et al. Effect of endotoxin on ventilation and breath variability: Role of the cyclooxygenase pathway. Am J Respir Crit Care Med 2001; 164:620-6.

10. Tobin MJ. Basing respiratory management of COVID-19 on physiological principles. Am J Respir Crit Care Med 2020;201:131920.

11. Mark RG, David AG. Respiratory conditions in coronavirus disease 2019 (COVID-19): Important considerations regarding novel treatment strategies to reduce mortality, Med Hypotheses 2020;40:109760.

12. Arjun R, Duraisamy AJ, Selvakumar B, Pal SV. Medicinal plants from Siddha system of medicine useful for treating respiratory diseases. Int $\mathrm{J}$ Pharm Anal 2009;1:20-30. 